\section{References}

Royal College of Psychiatrists (1991) Psychotherapy Specialist Section Working Group: The future of psychotherapy services. Psychiatric Bulletin, 15, $174-179$.

(1990) Report of the working group on the training implications of the move towards community orientated treatment. Psychiatric Bulletin, 14, 686-693.
- (1986) Guidelines for the training of general psychiatrists in psychotherapy. Bulletin of the Royal College of Psychiatrists, 10, 286-289.

Royal Medico-Psychological Association (1971) Guidelines for the training of general psychiatrists in psychotherapy. British Journal of Psychiatry, 119, 555-557.

STERN, R. (1993) Behavioural-cognitive psychotherapy training for psychiatrists. Psychiatric Bulletin, 17, 1-4.

\title{
A self-help group for women drinkers - a trainee's perspective
}

\author{
Denise RIORDAN, Registrar in Psychiatry, Edenfield Centre, Prestwich Hospital, \\ Bury New Road, Manchester M25 7BL
}

While working as a registrar on a Regional Alcoholism Treatment Unit (ATU), I took part in a weekly support group for women. This afforded a valuable insight into the way in which alcoholism affects women, and showed how a group could be used by its members in a variety of ways. It was an important and valuable learning experience which is not commonly available to trainees in psychiatry.

The unit is based in a teaching hospital and run by a multidisciplinary team. There are facilities for in-patient and out-patient detoxification, and longer term rehabilitation, including individual counselling and group support. The unit encourages clients to develop an individual support network which best suits their own needs.

\section{Background to the group}

The unit recognised early in its development the increasing number of women alcoholics being referred to services, and established a Women's Group to meet their needs. Initially the group had only a few regular attenders, but has expanded so that two groups are now held weekly, each attended by 25 to 30 clients.

A social worker and a member of the nursing staff facilitate the group. There is no set agenda and the participants can raise any issue they wish. It is an open group; some women have individual counselling prior to attendance, but this is not a prerequisite.

Ages range from the late teens to over 70 years. A broad spectrum of backgrounds are represented. Many women use other services including individual therapy and Alcoholics Anonymous. Some have had many years of sobriety ( 15 years or more) while others might have only a couple of days, and attend after starting on a detoxification programme. Between these two extremes, a wide range exists. Most of the women live independently, some in dryhouses, others in hostels. Several travel $\mathbf{3 0}$ miles or more to attend the group.

\section{Content of the discussions}

There was frequent talk about drinking, always in an air of openness and honesty, and frequently tinged with shame and guilt. Women would admit if they had relapsed into drinking and talk about the circumstances surrounding their doing so, always acknowledging their own responsibility. The focus was not so much on past drinking but more on coping with the present. Advice given and comments made were pragmatic and supportive. There was never any sense of disapproval towards those who were currently drinking. Instead, each looked for what could be learnt from the current relapse, and how that could help in the future. 
The women described a number of different tactics they had used to obtain alcohol, from spending their housekeeping money, to shoplifting, theft and deception. They also described ways in which they had tried to conceal their alcoholism, only to later discover that those around them had been fully aware of what they were doing. They frequently discussed relationships. A significant number expressed their amazement at the tolerance, help and support which they had received from their families, and their gratitude for this. Many others, however, had been rejected by both family and friends, and felt alienated and alone.

A striking feature was the amount of violence verbal, physical and sexual - which the women had endured. Reports of broken bones, cuts and bruises were common. Some had experienced more serious, even life-threatening injuries. During the period I attended the group several had significant injuries inflicted on them, mainly by their partners. For some this was in connection with their drinking, but for others it was not. The aggressor often, but not always, had a history of alcoholism.

Sexual violence was distressingly common, particularly that experienced while drunk. Many chose not to report these attacks to the authorities partly out of a sense of shame, but more from a fear that they would not be believed.

A poignant area of discussion surrounded children. Some of the women had lost custody of their children, and others were currently engaged in court proceedings to establish who would have it. In addition there were those who had successfully regained custody, sometimes against all expectations, as well as those who were in the process of reestablishing contact with their children. Common to all was a sense of guilt and betrayal, a sense that they had let their children down, caused them suffering, and a fear that the children would be permanently scarred by what they had done. The women found it hard to forgive themselves for this, and were afraid that their children would hate them.

Those who shared anxieties about pending court cases were given a lot of practical support, from a simple description of how the court was organised to offers of companionship on the day. Advice on other legal issues such as injunctions, separations and divorce was readily available from within the group.

It was interesting to hear how alcoholics viewed the medical profession. While many had received useful help and advice, it was common to hear the women describe a sense of rejection, with any complaint being dismissed as a consequence of their drinking. Even those who had prolonged periods of sobriety found that when faced with a condition completely unrelated to drinking, their general practitioner would fail to recognise their anxieties about it, focusing rather on the risk of a return to drinking.
This had occurred even when facing potentially lifethreatening disorders.

Many sessions focused on the early life of the women. Most had experienced some sort of abuse, physical, emotional or sexual. For many, the safety of the group enabled them to address painful issues for the first time. The group responded with great sensitivity and tact, listening and supporting, never pushing anyone to reveal more than she chose. The issues were given time and space by the women, who could cope well with long periods of silence, and would not rush in to change the topic. The group did not fail to remind the woman sharing her experiences that individual help was available if she wanted to discuss other things in more privacy.

\section{Comment}

During the groups I attended, I was impressed by the low self-esteem and lack of self worth which many of the women felt, but at the same time noted tremendous resilience and ability to cope with potentially overwhelming stress. They also had a great capacity to handle sensitive information appropriately, as well as a tremendous capacity for humour (although never a sense of bravado).

Some may be concerned that a large, open group dealt with sensitive issues such as sexual abuse. It was the philosophy of the group that its members used the time as they chose, and the facilitators were available out of the group for the women to approach if they wanted further help with any of the issues raised. I think the fact that some chose this as a forum to start dealing with painful topics reflects how successful and helpful they found the group.

Another area of concern may be that the women used a wide variety of agencies and therapies. We recognise that for recovering alcoholics there is no 'ideal' treatment package which will help everyone. Recovery is something that has to be worked on daily. If someone derives benefit from the help of several agencies, working separately, but with the same goal, then we would encourage them to use that combination.

Confidentiality is an important aspect of any group, but especially so in a large open group where sensitive issues are raised. Participants in this group were regularly reminded that issues raised in the group were not to be discussed outside, and during the time I was involved in the group there was never any concern that confidentiality was breached. In the past when there was concern that topics had been discussed inappropriately, the issue was taken seriously, and dealt with by both the staff and the participants of the group concerned.

Some may question the policy of having such a broad spectrum of drinking behaviour in the group, from those currently on a detoxification programme 
to those who had been sober for many years. I feel this breadth of experience was one of the real strengths of the group. Those new to the idea of sobriety gained from seeing people who had gone through a similar experience to themselves now enjoying happy and successful lives. Those whose families had broken up saw women whose families had re-formed following sobriety. Those who felt hopeless were greatly supported by hearing from people who had felt the same, but were now in control of their lives and their future. Everyone in the group, by virtue of their listening to others, was acting as a source of support to another individual. This gave a great sense of self worth to participants who felt they had nothing to offer to society.
Trainees in psychiatry have a lot of exposure to problem drinkers, especially when they are on call. They frequently see people in a drunken state - at times aggressive - making what seem to be unreasonable demands. The opportunity to have been involved with a group who seek to help themselves and others in a responsible and sympathetic manner has helped me to approach these people in a more positive and optimistic way.

\section{Acknowledgements}

I am grateful to Ms Evelyn Ward and Dr B.D. Hore for their comments, and particularly grateful to the women who allowed me to attend their group.

\section{Miscellany}

\section{International Psycho-Oncology Society}

Dr Lawrence Goldie, FRCPsych, has been elected Honorary Member of the International PsychoOncology Society (IPOS), one of the first three members of the Society of whom this honour has been conferred.

\section{National Alcohol Helpline}

The test phase of the London pilot for the National Alcohol Helpline started on 9 August 1993. Once this is completed it is planned for the service to become national in 1996. It will operate from 6 p.m. to 11 p.m. seven evenings a week and will provide a safe and anonymous place for information and help. The number is 0713320202.

\section{Depression in the elderly}

The LiNC-UP educational slide kit entitled 'Depression in the Elderly-New Approaches to
Old Problems' contains 24 slides accompanied by detailed notes and looks at a number of topics ranging from the issues of diagnosis and assessment in primary care to long-term management approaches. Contact Invicta Pharmaceuticals, A Division of Pfizer Ltd, Ramsgate Road, Sandwich, Kent CT13 9NJ (telephone 0304 616142) for a complimentary copy. For further information on GP educational materials available, contact the Public Education Department at the College.

\section{Care of mentally ill people in the community}

The Mental Health Foundation has launched an inquiry into the care of severely mentally ill people in the community. It will be the first to involve senior figures from the health, social services, criminal justice and housing fields. The Inquiry began in October 1993 and will report in April 1994. It will meet every month. Further information: The Mental Health Foundation, 37 Mortimer Street, London WIN 7RJ. 